\title{
Fichas de pesquisa de campo para estudo da tipografia nominativa na arquitetura carioca
}

\author{
Field research forms for a study on nominative typography in Rio de Janeiro city \\ architecture
}

Carlos Alexandre Xavier Salomon, Anna Paula Silva Gouveia, Priscila Lena Farias.

\begin{abstract}
tipografia arquitetônica, fichas, classificação
Este artigo discute a adaptação dos procedimentos metodológicos utilizados no projeto de pesquisa 'Paisagens Tipográficas' (PAT), desenvolvido pelo grupo 'Tipografia e Linguagem Gráfica' (Centro Universitário Senac) em parceria com o grupo 'Tipografia arquitetônica' (UNICAMP), para uma investigação da tipografia arquitetônica carioca (TAC). O artigo mostra como o sistema de catalogação desenvolvido para a cidade de São Paulo foi modificado e aplicado no contexto do centro histórico da cidade do Rio de Janeiro, possibilitando uma coleta de informações mais adequada a este ambiente urbano específico.
\end{abstract}

architectonic typography, record, classification

This article discusses the adaptation of the methodological procedures adopted by the research project 'Typographic Landscapes' (PAT), jointly developed by the research groups 'Typography and Graphic Language' (Centro Universitário Senac) and São Paulo City Architectural Typography (UNICAMP) for an investigation on Rio de Janeiro city architectural typography (TAC). The paper shows how the recording system developed for São Paulo city was modified and applied in the context of Rio de Janeiro city historical centre, endowing an information gathering more adequate to this specific urban environment.

\section{Introdução}

O projeto 'Paisagens tipográficas' (PAT) é desenvolvido pelos integrantes do grupo de pesquisa 'Tipografia e Linguagem Gráfica', credenciado no CNPq pelo Centro Universitário Senac, em parceria com o grupo de pesquisa 'Tipografia Arquitetônica' (TAP), credenciado no CNPq pela UNICAMP, com apoio da CAPES, CNPq e FAPESP. As pesquisas desenvolvidas por ambos, desde 2003, investigam os elementos tipográficos inseridos paisagem da cidade. No atual estágio, as pesquisas abordam especificamente a tipografia aplicada à arquitetura do centro histórico da cidade de São Paulo. A principal hipótese de trabalho é que seja possível identificar, nos casos onde há uma integração do elemento tipográfico com a arquitetura, matrizes culturais comuns aos desenhos de letras e à linguagem arquitetônica. Acredita-se que um estudo deste tipo possa contribuir tanto para a memória, identidade e patrimônio da cidade, quanto para uma melhor compreensão da arquitetura e do design de tipos no Brasil (Gouveia et al 2006 e [no prelo]). Esta investigação tem seus referenciais teóricos na psicologia ambiental, na epigrafia e no design da informação.

Para o levantamento realizado na cidade de São Paulo foi desenvolvido um sistema de fichas que possibilita o levantamento de campo, bem como a catalogação digital dos dados. Este sistema foi adaptado, e está sendo utilizado na coleta de dados da pesquisa 'Tipografia Arquitetônica Carioca' (TAC). A pesquisa carioca, em seu recorte atual, ao diferentemente da paulistana, que estuda todos os tipos de inserção de caracteres nos edifícios, objetiva exclusivamente a classificação da tipografia nominativa, isto é, aquela que, presente na fachada, nomeia os edifícios do centro histórico do Rio de Janeiro.

Uma das fontes para a pesquisa Tipografia Arquitetônica Carioca, o livro intitulado 'A tipografia na arquitetura do Rio de Janeiro' (Horcades, Martins \& Taborda 1986), é um dos poucos exemplos de levantamento deste gênero realizado no Brasil. Esta publicação teve como objetivo registrar e chamar a atenção do observador comum para o universo de letras 
presentes na paisagem do Rio de Janeiro. Apesar da sua importância, o trabalho, que apresenta imagens dos mais diversos tipos de letreiramentos encontrados em toda a cidade, não tem em sua gênese uma catalogação feita com os critérios rigorosos de uma pesquisa acadêmica. A obra, hoje esgotada, resultou de um trabalho de final de curso de graduação, e é uma mostra do que a cidade do Rio de Janeiro tem a oferecer para aqueles que queiram fazer dela seu objeto de pesquisa. No contexto internacional, algumas referencias importantes para investigações nesta linha são Nicolete Gray (Gray 1960), Alan Bartram (Bartram 1975), Jock Kinneir (Kinneir 1980), Phil Baines e Catherine Dixon (Baines \& Dixon 2003).

\section{A arquitetura, a memória e o patrimônio histórico}

A importância histórica e cultural da cidade do Rio de Janeiro para o Brasil pode ser aferida em diversos aspectos. Herança dos tempos em que foi sede da Coroa Portuguesa e capital da República, o centro do Rio acolhe um conjunto de edifícios públicos e privados de grande relevância arquitetônica. Muitas destas obras não se encontram, ocntudo, em boas condições de conservação. Apesar disto, uma parte importante desta memória está sob a proteção de leis e decretos. Autarquias municipais, órgãos estaduais e federais são responsáveis por garantir que as leis de proteção do patrimônio histórico protejam a integridade física deste sítio.

Para a correta compreensão do objetivo da pesquisa sobre a inserção da tipografia na arquitetura carioca, é preciso explicar alguns conceitos. Segundo a SEDREPAHC" , "o bem preservado" deve ser entendido como pertencente "a um conjunto arquitetônico cujas características representem a identidade cultural de um bairro, localidade ou entorno de um bem tombado". Sendo assim, devem ser "mantidas as fachadas, os telhados e a volumetria". Modificações internas serão permitidas, "desde que se integrem aos elementos arquitetônicos preservados", pois o objetivo da preservação de um bem "é manter a ambiência urbana".

O recorte espacial e temporal da pesquisa Tipografia Arquitetônica Carioca baseia-se nas resoluções das autarquias responsáveis pelas políticas públicas de proteção e conservação do patrimônio cultural nas áreas de proteção do ambiente cultural do Rio de Janeiro. Uma destas resoluções criou as Áreas de Proteção do Ambiente Cultural (APAC). Todos os bens situados dentro do perímetro destas áreas se encontram em situação de preservação. A região do centro da cidade, através da Lei $n^{\circ} 506$ de 17 de janeiro de 1984, do PA 10.290 (Decreto $n^{\circ}$ 4.141/83) e da Lei 506/84, ganhou 4 destas áreas, que formam o conjunto denominado Corredor Cultural e abrangem trechos não-contínuos cujos perímetros são determinados por ruas e pontos específicos do espaço urbano (figura 1). Segundo o Instituto Municipal de Arte e Cultura, as 4 áreas foram determinadas em função de seus usos, atividades, arquitetura e ambiência (IMAC, 2002).

\footnotetext{
${ }^{1}$ Secretaria Extraordinária de Promoção, Defesa, Desenvolvimento e Revitalização do Patrimônio e da Memória Histórico-Cultural da Cidade do Rio de Janeiro. Disponível em <http://www.rio.rj.gov.br/sedrepahc/apac.shtm>. Acesso em 25 de fevereiro de 2009.
} 


\section{Infodesıgn}

Figura 1: As 4 áreas da APAC no centro da cidade do Rio de Janeiro.

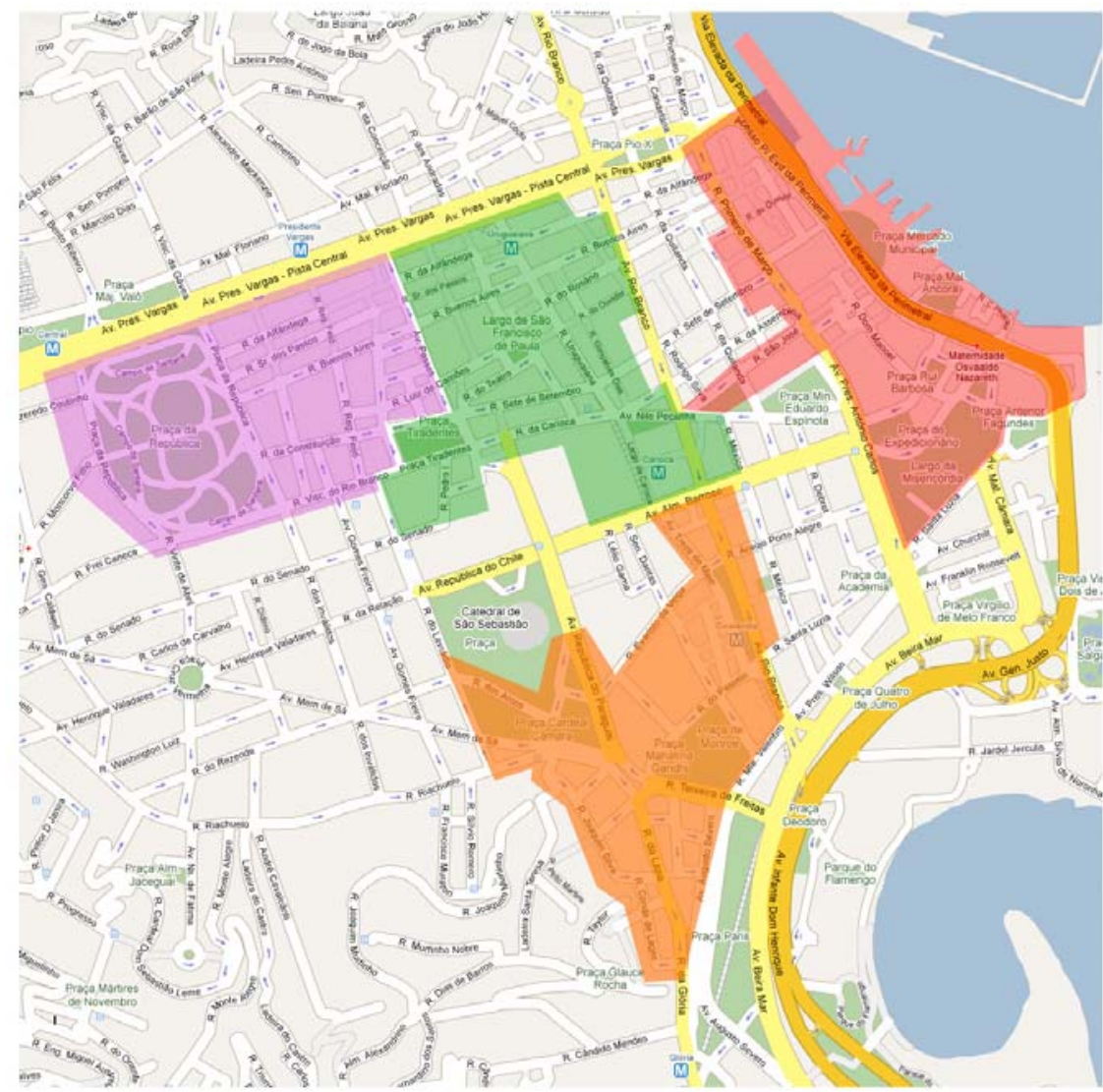

Por sua vez, a conceituação de bem tombado deve ser compreendida também através do artigo $1^{\circ}$ do capítulo I do Decreto-Lei número 25 de 30 de novembro de $1937,{ }^{2}$ que define patrimônio histórico e artístico nacional como "o conjunto dos bens móveis e imóveis existentes no país e cuja conservação seja de interesse público, quer por sua vinculação a fatos memoráveis da história do Brasil, quer por seu excepcional valor arqueológico ou etnográfico, bibliográfico ou artístico". Esta definição se completa com o artigo $4^{\circ}$ do capítulo II que define que os bens do conjunto acima citado devem estar inscritos como obras nos quatro livros de Tombo do Serviço do Patrimônio Histórico e Artístico Nacional.

Nas quatro áreas de APAC do centro do Rio de Janeiro, encontramos um total de 76 bens (figura 2) que pertencem ao patrimônio histórico e são inscritos nos livros de Tombo, sendo portanto, protegidos. Os órgãos responsáveis pela política pública de conservação deste patrimônio são a SEDREPAHC (municipal), o INEPAC (Instituto Estadual do Patrimônio Cultural) e o IPHAN (Instituto de Patrimônio Histórico e Artístico Nacional), sendo os bens em questão tombados por pelo menos um dos três órgãos.

2 Disponível em <https://www.planalto.gov.br/ccivil_03/decreto-lei/Del0025.htm>. Acesso em 10 de janeiro de 2009. 
Figura 2: Localização dos 76 bens tombados que se encontram dentro das 4 áreas da APAC no centro da cidade do Rio de Janeiro.

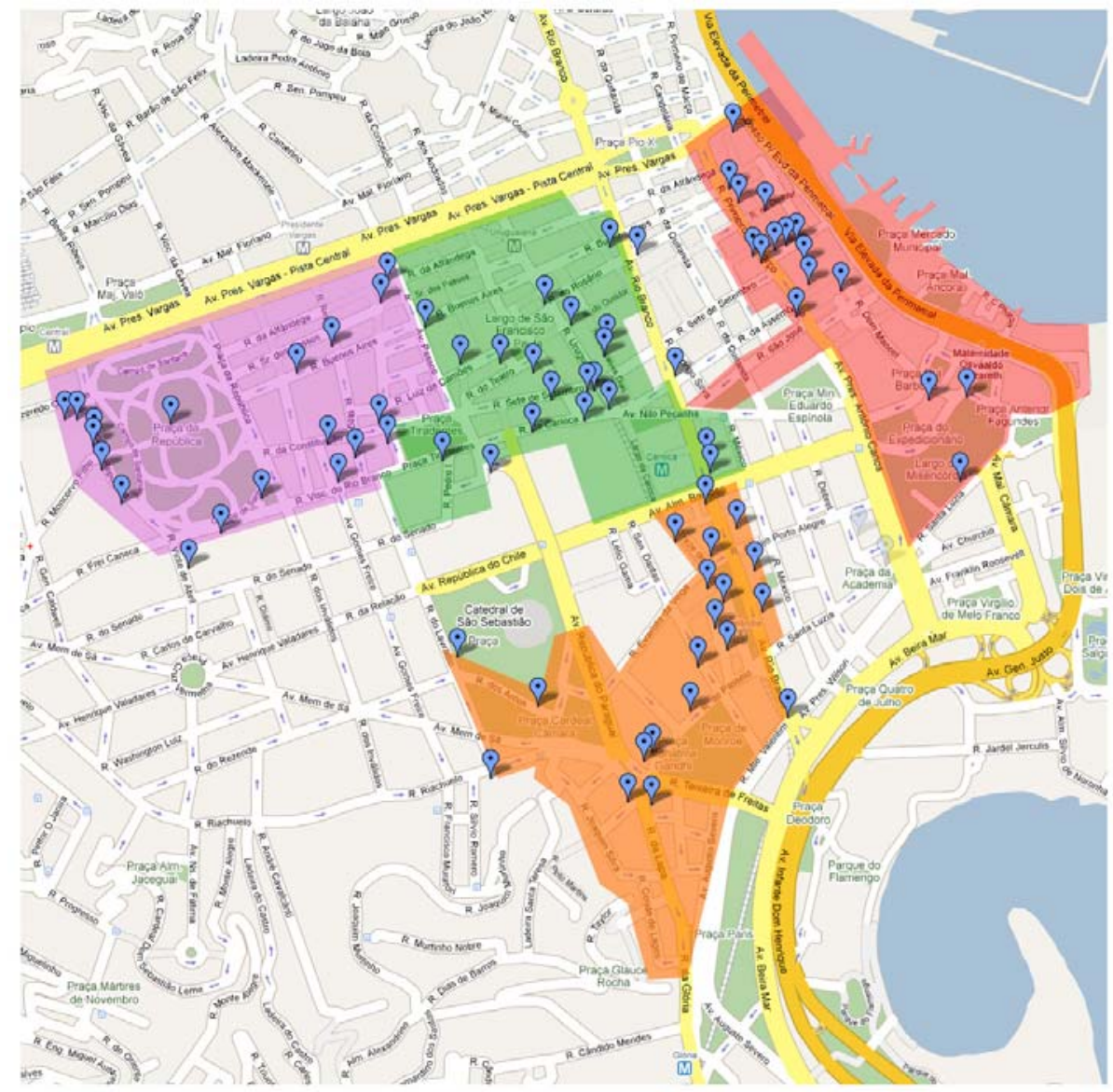

\section{Coleta de dados}

Para a realização de um registro preciso dos elementos tipográficos presentes nos 76 edifícios tombados, foi primeiramente realizado um planejamento para a coleta de dados. A partir da identificação dos bens tombados dentro das áreas APAC, foi elaborado um mapa (figura 2) com a localização de todos os edifícios. O próximo passo foi a concepção de um banco de dados, para o qual utilizou-se, inicialmente, o sistema de catalogação desenvolvido pela equipe responsável pelo projeto de pesquisa Paisagens Tipográficas para a investigação da tipografia arquitetônica paulistana. O sistema criado pela equipe é composto por cinco modelos distintos de fichas, contendo campos diversos, de acordo com a tipo de elemento tipográfico que está sendo registrado.

No projeto Paisagens Tipográficas, a participação de pesquisadores de áreas diversas (arquitetura, design, história, geologia e fotografia) contribuiu para que as fichas de pesquisa de campo abrigassem uma coleta de dados mais ampla do que o simples levantamento de estilos tipográficos inicialmente cogitado. O projeto conta, assim, com quatro fichas (Gouveia et al 2007):

- Ficha A: dados sobre a identidade do edifício, com campos para nome, localização, uso atual, referências, nome do arquiteto ou construtora, data de construção, informações sobre tombamento.

- Ficha B: dados sobre a inserção do nome do edifício na portada da edificação, com especificações sobre o tipo de letra, composição e materiais utilizados. 


\section{Infodesıgn}

- Ficha C: dados sobre epígrafes arquitetônicas (assinaturas de arquitetos e contrutores na fachada do edifício), com especificações sobre o tipo de letra, tipo de gravação e caracterização da rocha na qual aparece a inscrição.

- Ficha D: dados sobre os demais elementos tipográficos inseridos no edifício, tais como números, caixas de depósito noturno e de correios, denominados 'objetos e apliques', com especificações sobre o tipo de inserção, tipo de letra, composição e materiais utilizados.

Um primeiro estudo exploratório dos 76 edifícios tombados dentro das áreas APAC, contudo, revelou que nenhum deles continha epígrafes arquitetônicas. $O$ estudo revelou também que alguns imóveis apresentavam o nome do edifício em mais de um local, ou em local que não correspondia exatamente à portada, enquanto elemento arquitetônico. Tais observações indicaram a pertinência de um recorte mais específico dentro do estudo da tipografia arquitetônica carioca, deixando de lado elementos tipográficos que não se referissem especificamente ao nome do edifício tombado. Os elementos preservados por tal recorte foram denominados 'tipografia nominativa'.

O estudo exploratório apontou, ainda, a necessidade de adaptação das Fichas A e B originais do projeto Paisagens Tipográficas, de forma a otimizar a coleta de dados para $O$ estudo carioca. A principal alteração na Ficha $A$ foi a inclusão de campos para a descrição do estilo arquitetônico e observações sobre estado e uso do imóvel. Quanto à Ficha B, no contexto da pesquisa paulistana, esta coletava dados sobre a inserção da tipografia na portada ${ }^{3}$ do edifício. Com base nos levantamentos preliminares realizados no Rio de Janeiro pôde-se verificar que, no caso da tipografia arquitetônica carioca, o nome do edifício não estava associado diretamente à portada, mas em muitos casos apresentava-se disposto em outros pontos da fachada (paredes cegas, frontões, platibandas, etc.). Optou-se, assim, por classificar os dados da Ficha B não mais como relativos à 'tipografia da portada' mas à 'tipografia nominativa'. Se compararmos os resultados preliminares de uma e outra pesquisa (em especial Gouveia et al 2004), nota-se que no caso carioca o nome do edifício ganha ênfase no que concerne à dimensão, pois, em muitos casos, os letreiramentos ocupam grande parte da fachada. Ele também se destaca no que concerne à variedade de inserções, aparecendo de formas, tamanhos e em localizações muito variadas e diferentes das encontradas no caso da pesquisa paulistana.

A adaptação realizada para o levantamento da tipografia arquitetônica dos edifícios do Rio de Janeiro resultou, portanto, no desenvolvimento de apenas duas fichas, uma das quais pode se desdobrar caso o edifício contenha mais de um elemento de tipografia nominativa. A Ficha A/TAC registra dados sobre a identificação do imóvel, incluindo observações sobre aspectos arquitetônicos do edifício (figura 3). A Ficha B/TAC registra e detalha os elementos de tipografia nominativa (figura 4). Através de um recurso de numeração, a Ficha B/TAC pode se transformar em uma série de fichas que descrevem os diversos elementos de tipografia nominativa presentes em um mesmo edifício (por exemplo, fichas B1, B2, B3, etc).

Em uma segunda etapa, na qual foram feitos os primeiros testes de levantamento de campo, foi realizada uma reordenação dos campos nas respectivas fichas, bem como uma adequação de alguns termos denominativos de campos. As fichas foram diagramadas em formato $\mathrm{A} 4$. $\mathrm{O}$ campos superiores, numerados de 1 a 5 são comuns às duas fichas. Os demais campos foram adaptados e reestruturados.

A Ficha A/TAC (figura 3 ) tem a seguinte estrutura: $O$ campo 6 se refere às coordenadas em graus, o campo 7 classifica o estilo arquitetônico do imóvel. A data do projeto aparece no campo 8 , e a data de construção é registrada no campo 9 . A referência sobre a autoria do projeto fica no campo 10, e, sobre o construtor, no campo 11. O campo 12 classifica o estado em que se encontra o imóvel. Os próximos campos, 13 e 14, procuram coletar informações sobre o uso original e o uso atual do imóvel, respectivamente. O campo 15 traz o registro do mapa com a localização do imóvel na malha urbana, enquanto o 16 é reservado para a imagem digital do imóvel. O campo 17, finalmente, fica reservado para observações adicionais que o responsável pelo levantamento queira fazer.

3 Neste contexto, entende-se portada como o conjunto formado pela porta principal mais ornamentos ou elementos arquitetônicos que a compõem, como colunas, entablamentos, escada, etc. (para uma análise da tipografia nas portadas paulistanas ver Gouveia et. al. 2004). 
Carlos Alexandre Xavier Salomon, Anna Paula Silva Gouveia, Priscila Lena Farias | Fichas de pesquisa de campo para estudo da tipografia nominativa na arquitetura carioca

A Ficha B/TAC (figura 4) coleta dados específicos sobre a tipografia nominativa. O campo 6 registra as medidas, em metros. O campo 7 localiza a tipografia de forma visual no imóvel. A transcrição do conteúdo está no campo 8 . O campo 9 é reservado para a autoria do projeto da inscrição tipográfica. O campo 10 e 11 apresentam a classificação tipográfica por família, uso ortográfico, peso, inclinação, alinhamento, material e relevo. O campo 12 abriga o registro visual num plano geral, isto é, sua posição e proporção em relação ao imóvel, e uma imagem em detalhe da tipografia. O campo 13 fica reservado para as demais observações.Figura 3: Ficha A da pesquisa Tipografia Arquitetônica Carioca.

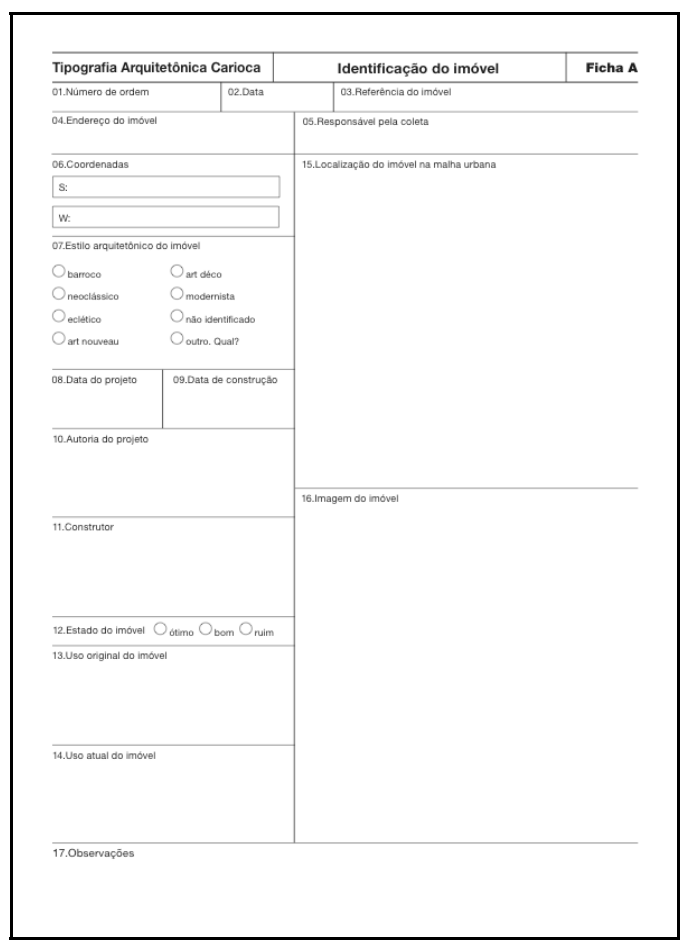

Figura 4: Ficha B da pesquisa Tipografia Arquitetônica Carioca.

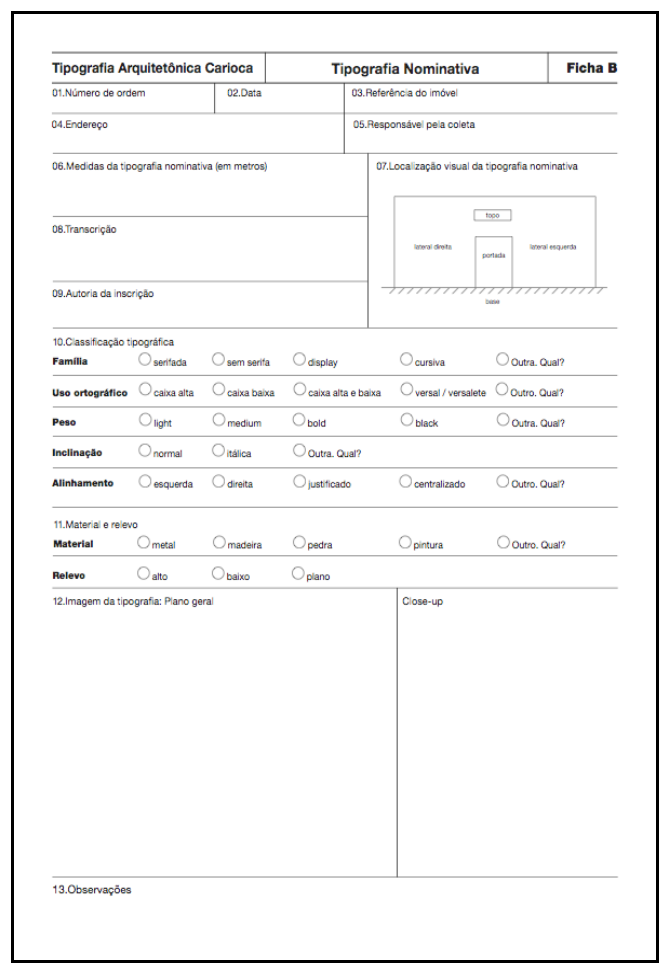




\section{Infodesıgn}

Caso haja mais de uma incidência de tipografia nominativa no mesmo imóvel, a ficha B vai se desdobrar em tantas instâncias quantas forem necessárias para descrever individualmente cada um destes elementos. Um exemplo disso é o edifício que abriga o Real Gabinete Portuguez de Leitura, que apresenta 3 incidências de tipografia nominativa (figuras 5 e 6). Neste para este edifício, foram criadas tres fichas (B1, B2 e B3), uma para cada ocorrência.

Figura 5: Fachada do Real Gabinete Portuguez de Leitura com indicação das três ocorrências de tipografia nominativa: no alto ao centro, e abaixo, nas duas colunas. Foto de Carlos Alexandre X. Salomon.

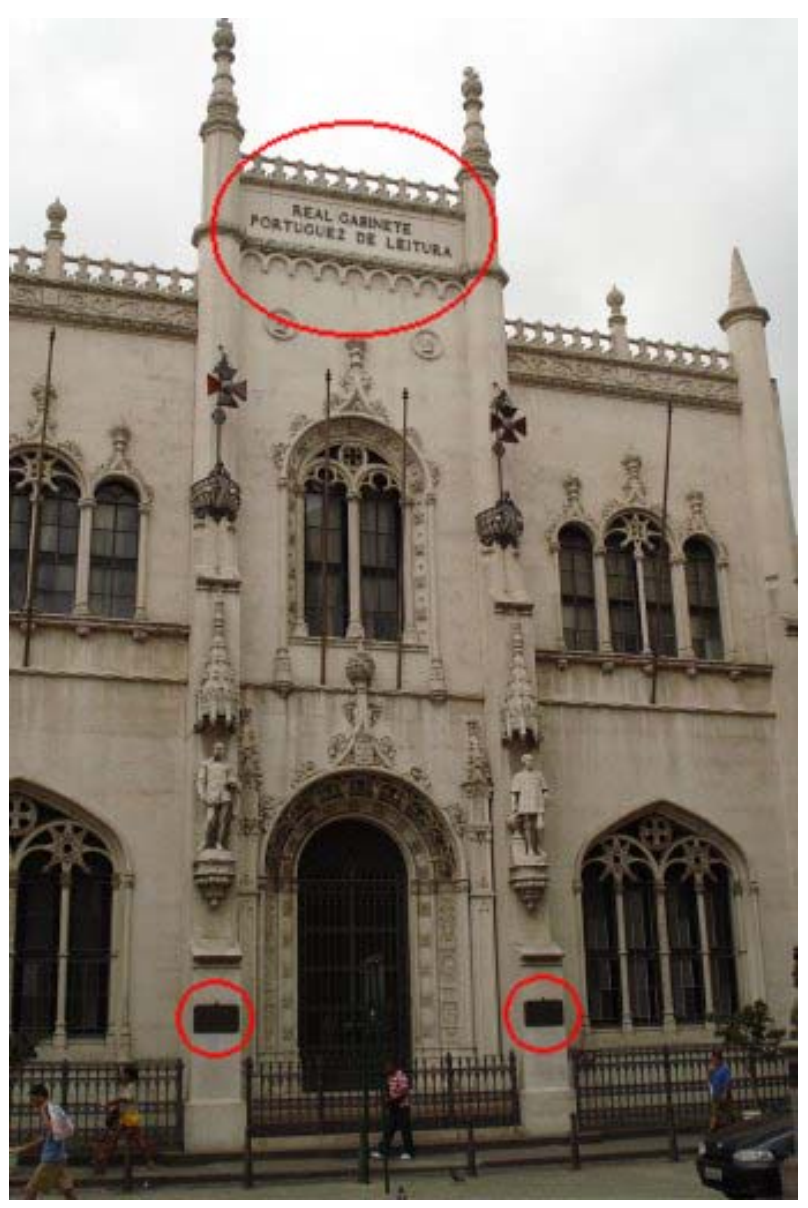

Figura 6: Detalhe da tipografia nominativa que ocorre em uma das colunas do Real Gabinete Portuguez de Leitura. Foto de Carlos Alexandre X. Salomon.

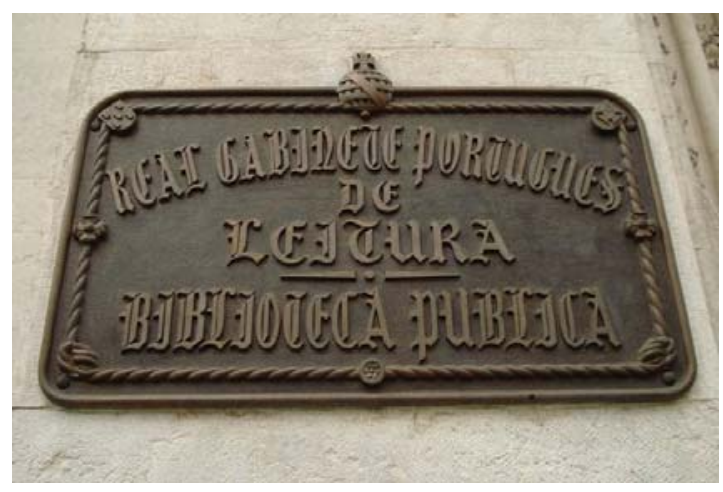

A coleta de dados é realizada seguindo-se uma ordenação geográfica, ou seja a ordem da coleta é estabelecida por um percurso definido com o auxílio do mapa com a localização dos edifícios. Essa ordem é registrada no campo 1 das fichas A e B (número de ordem). O 
resultado deste trajeto é o roteiro de coleta, isto é, uma rota no espaço urbano que serve para facilitar a locomoção e a localização de todos bens pesquisados.

O registro fotográfico para a pesquisa é realizado com equipamento digital. Este formato permite facilidade de armazenamento, transporte, manipulação e inserção das imagens nas fichas. Depois de editadas, as imagens passam a fazer parte de um acervo digital, que inclui outros tipos de documentos como textos, planilhas e mapas, e pode ser compartilhado.

Os registros fotográficos, sempre que possível, focam o detalhamento da tipografia nominativa, através da captura de imagem em visão frontal, evitando distorções. Tais registros também levam em conta a visão do observador transeunte, que caminha pelo espaço urbano e estabelece uma relação com a paisagem através da visão serial (Cullen 1971). Desta forma, espera-se obter subsídios para uma posterior avaliação da paisagem no que concerne principalmente à legibilidade da tipografia arquitetônica.

\section{Considerações Finais}

Este artigo procurou demonstrar como procedimentos elaborados para uma determinada pesquisa sobre tipografia arquitetônica podem ser modificados e utilizados em outro local, respeitando-se as características da pesquisa original, e, ao mesmo tempo, adaptado os instrumentos de pesquisa a outro contexto urbano e cultural. As fichas de coleta de dados para investigações sobre tipografia arquitetônica paulistana, desenvolvidas pela equipe responsável pelo projeto Paisagens Tipográficas, foram adaptadas para otimizar o registro de informações sobre um aspecto específico da tipografia arquitetônica carioca: a tipografia nominativa.

As adaptações foram feitas a partir de testes realizados em estudo exploratório e em uma primeira fase de coleta de dados. $\mathrm{O}$ uso das fichas rapidamente apontou a pertinência de um recorte mais preciso para a pesquisa, e a definição deste recorte, por sua vez, levou ao aprimoramento das fichas, de seus campos, e de sua organização gráfica. As fichas de pesquisa de campo, portanto, mostraram-se eficientes tanto enquanto ferramenta de coleta de dados quanto como instrumento heurístico de apoio à pesquisa.

É possível assim concluir, portanto, que os métodos e procedimentos desenvolvidos pelo projeto Paisagens Tipográficas, no contexto de pesquisas sobre tipografia arquitetônica paulistana, são suficientemente flexíveis e robustos para serem adaptados e aplicados a outros contextos, como os estudos sobre a paisagem tipográfica carioca. As novas fichas de pesquisa de campo aqui descritas, por sua vez, mostraram-se eficientes para captar as especificidades da tipografia nominativa carioca.

\section{Agradecimento}

Os autores agradecem à CAPES - Coordenação de Aperfeiçoamento de Pessoal de Nível Superior, ao CNPq - Conselho Nacional de Desenvolvimento Científico e Tecnológico e à FAPESP - Fundação de Amparo à Pesquisa do Estado de São Paulo pelo apoio financeiro concedido para suas pesquisas.

\section{Referências}

BAINES, Phil \& DIXON, Catherine 2003. Signs: lettering in the environment. London: Collins Design.

BARTRAM, Alan 1975. Lettering in architecture. London: Lund Humphries.

CULLEN, Gordon 1971. Paisagem urbana. Lisboa: Edições 70.

GOUVEIA, Anna Paula Silva; Farias, Priscila Lena; Pereira, André Luiz Tavares \& Gallo, Haroldo [no prelo]. Epígrafes arquitetônicas: assinaturas dos arquitetos e construtores da cidade de São Paulo. Oculum. 


\section{Infodesıgn}

GOUVEIA, Anna Paula Silva; FARIAS, Priscila Lena; PEREIRA, André Luiz Tavares; GALLO, Haroldo; \& FERNANDES, Luiz Alberto 2006. Tipografia arquitetônica paulistana: resultados de um estudo piloto. Anais do $7^{\circ}$ Congresso Brasileiro de Pesquisa e Desenvolvimento em Design. Curitiba: AEND Brasil.

GOUVEIA, Anna Paula Silva; PEREIRA, André Luiz Tavares; FARIAS, Priscila Lena \& BARREIROS, Gabriela 2007. Paisagens tipográficas: lendo as letras na cidade. InfoDesign - Revista Brasileira de Design da Informação vol.4 n.1: 1-12.

GOUVEIA, Anna Paula Silva; PEREIRA, André Luiz Tavares; GALLO, Haroldo; FARIAS, Priscila Lena \&; FERNANDES, Luiz Alberto 2004. Tipografia arquitetônica Paulistana. Os textos das portadas dos edifícios do centro histórico. Anais do $6^{\circ}$ Congresso Brasileiro de Pesquisa e desenvolvimento em Design. São Paulo: FAAP.

GRAY, Nicolete 1960. Lettering on buildings. New York: Reinhold.

HORCADES, Carlos M.; MARTINS, Nelson \& TABORDA, Felipe 1986. Tipografia na arquitetura do Rio de Janeiro. Rio de Janeiro: Index.

IMAC - INSTITUTO MUNICIPAL DE ARTE E CULTURA 2002. Corredor Cultural: como recuperar, reformar ou construir seu imóvel. Rio de Janeiro: Prefeitura do Rio de Janeiro.

KINNEIR, Jock 1980. Words and buildings, the art and practice of public lettering. London: Architectural Press.

\section{Sobre os autores}

Anna Paula Silva Gouveia, arquiteta e doutora pela FAU USP, é professora do Instituto de Artes da UNICAMP e do Centro Universitário Senac. É lider dos grupos de pesquisa "Tipografia Arquitetônica" e "Design Criativo da Forma", atuando principalmente nos seguintes temas: cor e tipografia aplicada à paisagem urbana, desenho, metodologia de projeto e ensino. Integra a atual diretoria da Sociedade Brasileira de Design da Informação - SBDI.

Carlos Alexandre Xavier Salomon, designer gráfico pela UniverCidade e bacharel em Comunicação Social pela PUC de Campinas. É mestrando em Design no Centro Universitário Senac (SP) e bolsista da Fapesp. Autor de projetos gráficos editoriais, entre eles os livros Manual Tipográfico Brasileiro (Ateliê Editorial), A Evolução da Escrita (Editora Senac Rio), De corpo e Alma - Theatro José de Alencar (Governo do Ceará).

Priscila Lena Farias, designer gráfica, é professora da FAUUSP e do Mestrado em Design do Centro Universitário Senac, e bolsista de produtividade em pesquisa do CNPq. É lider dos grupos de pesquisa História, Teoria e Linguagens do Design (USP) e Tipografia e Linguagem Gráfica (SENAC/SP). É organizadora dos livros Fontes digitais brasileiras (Rosari) e Advanced Issues on Cognitive Science and Semiotics (Shaker Verlag), autora de Tipografia digital (2AB), e de vários artigos sobre tipografia, design e semiótica. priscila.farias@pq.cnpq.br 